\title{
The System of Formation of Compensatory Factors in Blind Musicians in the Solfeggio Lessons
}

\author{
Galima Lukina \\ State Institute of Art Studies \\ Russian State Specialized Academy of Arts \\ Moscow, Russia \\ lukina@sias.ru
}

\begin{abstract}
The article describes the characteristics of teaching methods of solfeggio, aimed at the development of compensatory factors in blind children. In this article there is the solution of specific problems of the teaching solfeggio for the blind and visually impaired children at the children's music school; it takes into account the need for the development of compensatory factor of lost vision. In case of impairment or loss of visual functions, the artistic potential of a person is the most secure when applied to music and that art acts as an optimal field for the artistic development of blind and visually impaired. The author focuses on methods that can help student realize the need to think, to feel, to learn, to create, to discover meaning. This is the only possible way to bring his life into creative search and realization of full artistic activity.
\end{abstract}

Keywords-art special education; inclusive education; music pedagogy; teaching methods of solfeggio; specialized methodology; the visually impaired and blind students

\section{INTRODUCTION}

In Russia there has been formed a continuous system of music education for the visually impaired, the elements of which are School 1- College (Kursk musical Collegeboarding school for the blind) - University (Russian State specialized Academy of Arts). However, often the effective creative growth of students in these educational institutions is hampered by serious shortcomings at an early stage of music education in the children's music school, which are associated with the lack of appropriate approaches and methods of teaching. A special role in the formation of the young musician is given the subject "Solfeggio". It is in the solfeggio lessons the child acquires the skills of singing, develops musical literacy, trains the musical ear, gets the first aural art impressions and experience of collaborative musical creativity in a group of peers.

It would seem that the results of theoretical and practical research indicate the identity of the nature of musical abilities of blind and seeing children. This gives grounds to assert that musical tiflopedagogics (pedagogy for blind and

Specialized music school for blind and visually impaired children of Armavir, the Kostroma boarding school, the Moscow boarding school No. 1 for blind children named after V. J. Yeroshenko, similar to the music boarding schools in Kislovodsk, Perm, Bataisk (the Rostov Region ) and several other cities. visually impaired) is based on a shared musical and pedagogical principles.

However, with the detection from these principles the most significant for the training and education of musicians with special needs, there is a shift of semantic emphasis and correction of pedagogical methods. This is due to the influence of vision limitations for the learning activity and age characteristics of students.

The authors have developed teaching methods of solfeggio based on such important mechanisms of compensation of blindness as a musical-auditory presentation, singing, tactile-motor sensations, memory, music system by L. Braille, that makes the process of teaching children with a lack of vision more accessible and effective. Thus, it is necessary to understand the importance of creative contact of the teacher and students based on mutual understanding and cooperation.

The process of teaching blind children solfeggio is presented in this article as a balance between specific difficulties and some advantages in work with blind people. So, the unavailability of sheet reading (score reading) is compensated by the development of memory, the lack of visual perception allows the learner focus better on own auditory sensations. Correction and compensation of the defect, according to L. S. Vygotsky, is the search for new "workarounds development"; these processes occur mainly in the area of abstract thinking, logical memory, voluntary attention.

From long ago people have noticed that with loss of any organ, the life of the organism changes, - for example, the loss of vision activates hearing and memory. Compensation can be defined as the universal ability of the body to compensate violations or loss of certain functions. Simply put, human nature is arranged in such a way that taking away some ability, it certainly compensates it with other possibilities.

As an art example of such a type of compensation can be the story of a hero from the novel by V. Korolenko "The Blind Musician": "Uncle Maxim was convinced more and more that nature failed the boy in sight, not hurt him in other ways; he was the creature who felt the available external impressions with remarkable fullness and power. And uncle 
Maxim thought that he was aimed to develop inherent potential of the boy".

Real experience with grownup blind musicians, including students from RSSAA, shows the result of education of their inclinations. In addition to musical abilities, teachers pay attention to the excellent memory of the blind students, their amazing attentiveness, ability to concentrate here and now, analytical thinking, openness to new knowledge, amazing subtlety of touch and a special responsibility. These qualities are sort of the goal of the teacher who works with blind children.

The material is based on long experience of the RSSAA teachers who worked with blind and visually impaired students from the Music Department (Yu. P. Antonov, I. G. Brodskaya-Karelina, T. P. Varlamov, V. I. Gorbaty, M. I. Imhanitsky, V.I. Lisovoy, E. V. Moroshkin, I. V. Syroezhkin, M. S. Filatov-Skrebkov and A. N. Yakupov).

\section{THE COMPLEX OF TEACHING METHODS OF SOLFEGGIO DEVELOPINGTHE COMPENSAT ORY FACTORS IN BLIND CHILDREN}

The modern teaching of the subject "Solfeggio" in the children's music school is characterized by a variety of pedagogical approaches to the perception of educational material. The priority is given to the complex of pedagogical techniques, which implementation allows organizing the educational process more efficiently. Teacher have to take into account the different degree of preparation of students, store of knowledge, the level of development of the necessary skills, musical and artistic preferences, the current musical and artistic taste, and inherent natural creative abilities in each of them.

The main qualities that will help the teacher, who works with blind children, to cope with any challenging circumstances are the methodological flexibility, creativity and, of course, unconditional love for children and work. As L. I. Plaksina notes: "Based on the theory of compensation, we should know, that the power of disease can resist the power of the spirit, which disabled person is able to get from creative activities" [1]. It should be emphasized that specific problems in work with blind and visually impaired students cannot be considered separately. They are closely intertwined with general psychological, pedagogical and methodical problems of teaching children of different age groups in children's music school.

From the very first solfeggio lessons it is important to form gradually in child responsiveness to the beauty of music, interest, attention, musical memory, inner hearing, figuratively-associative relationships (imagination), speech designation, auditory-motor connection - in other words the main compensatory factors in blind children. The system of compensatory factors in connection with teaching blind people music was first formulated in the dissertation by V. N. Kulakov [2]. On the basis of this system he developed methodology of work with blind bayan- and accordionplayers. In our work his methods are adapted to the subject "Solfeggio".
The complex of teaching methods in modern tiflopedagogics develops compensatory factors in blind children - taking it into account and especially for the subject "Solfeggio" we have tried to reflect a system of pedagogical management, including the following teaching methods: musical illustrations, tactile-motor performance, formative movements, re-intoning and the development of creative imagination, multiple repetition, verbal and figurative characteristics, collaborative creativity (ensemble singing). Let us briefly consider each of these methods.

\section{THE METHOD OF MUSICAL ILLUST RATION}

The method of musical illustrations involves the using of auditory and tactile visibility in the pedagogical process. It is based on a peculiar to children the tendency to imitate various sounds and movements from an early age. The visual display will be replaced by either musical illustrations (hearing the whole small musical composition or its fragment in the performance of the teacher or in the record), or tactile-motor performance (for example, to acquire skills of conducting), or using a visibility imitation (when children repeat performance after the teacher).

Blindness and low vision are the factors that limit the possibility of communication of the child with the environment, thereby integrating the range of sensory perceptions. Therefore, the more various palette of sound illustrations will form the more complete child's view of the world, musical and artistic ideas about it.

Using this method figuratively-associative thinking is developed. An important stimulus for the development of associative compensatory factors is the identification and impact of speech fundamentals of musical intonation in all its variety and wide range of register or timbre brilliance.

There are a great amount of typical intonational structures, which semantic meanings correspond to the depths of historical memory, intuitive representation of a particular emotion. Here are vivid examples of the musical literature, such as plays "Mama", "The Sick Doll" from "Children's Album" by P. I. Tchaikovsky, "A Poor Orphan" from "Album for the Youth" by Robert Schumann, "Crybaby, Playful girl, Bearcat" by D. B. Kabalevsky; the listing can be continued, noting those works in which according to $\mathrm{V}$. V. Medushevsky, "music is able to display many of the physical characteristics of emotional speech with great precision: the length of the sentences, their rhythmical organization (smooth or choppy, uneven, rich in pauses), tessitura, pitch line, with its ups and downs, the harshness or softness of the accents, timbre, and through this in the end - to reproduce the emotional state" (emphas is added).

Timbral colouring of the sound is similar to the effects on listener of the speech intonation and that stimulates the imagery and auditory representation in blind musician. And the more expressive, original this sound, the brighter its trace in the mind of the child. And in this connection, the problem of selecting the training material is no less acute than in other pedagogical situations. Thus, the sound characteristics of the characters in Prokofiev's orchestra suite "Petya and the Wolf" are inextricably linked with timbres, which in many 
respects determined the textbook status of this work in the educational repertoire.

The value of an artwork for a child is formed by the influence of musical expressiveness. The developed imagination, the ability to represent a sounding image in consciousness, the possibility of including associative auditory representations largely compensates for the lack of vision.

The lessons that are accompanied by the use of musical illustrations contribute to the accumulation of musicalauditory experience of the student, stimulate the imageemotional sphere, activate and support interest in musical studies. Since a full reading of notes from a sheet by the Braille system is not always possible2, thanks to the method of musical illustrations the student gets acquainted with beautiful melodies, consonances, forms of classical compositions that replenish his auditory artistic baggage, developing aesthetic taste. So, through the first wonderful musical impressions the child is attached to the creativity of great composers that personally elevates his soul.

\section{THE METHOD OF MULTIPLE REPETITION}

When using this method, it is important not the automatism of repetition 3 of motives, phrases, me morization of elements of a melodic pattern as such. It is necessary for the child to listen attentively to the artistic expressiveness, beauty of the melody, each of its constituent elements (consonance or intonation-rhythmic turnover). This method is used to achieve the effect of aesthetic pleasure and experience of feeling the creative freedom in the performance of the melody, learned in details and in general, and, ultimately, contribute to the development of intonational hearing.

\section{THE METHOD OF VERBAL AND FIGURATIVE AND SEMANTIC CHARACTERIST ICS: METHOD OF INITIAL INTONATIONAL ANALYSIS}

The method of verbal and figurative characteristics, in fact, coincides with the methods of music observation (B. Asafiev), reflections on music (D. Kabalevsky). It allows to bring up in the student a special intonational sensitivity, the ability to listen and hear music integrally, encompassing its external sound side and its inner content-semantic "filling".

"Behind the intonation alive man is hidden", - a man, who have learned the true beauty (V. V. Medushevsky). This understanding of the essence of music is the key to children's perception of a particular image, personality of the composer and his style.

\footnotetext{
2 Not all educational institutions have textbooks on solfeggio, set out in the Braille system.

Colleagues from China Sun Yang, Huang Yu E, Shan Jiu Xuan in the article "Experience teaching of blind and hard of hearing pianists, flutists and violinists in China" using the method of multiply repetition note that thanks to it the teacher achieves that the children "gradually memorized these elements to their free repetition and even to automatism" [3].
}

During the dialogue with the students the teacher performs a verbal description of the melody that he chose for dictation or singing. In the initial lessons, the dialogue can be based on the establishment of associative links with other musical and artistic works, analogies with emotional experiences, feelings and conditions, searching for sound equivalents to the sounds of nature, tactile ideas of various materials (cold metal, soft velvet, tender silk), touch aromas, taste. This will allow to "grab" the musical image intuitively, instantly, sometimes subconsciously picking up and accumulating its essential characteristics, and on this basis to understand the laws of artistic and imaginative thinking inherent in both the epoch and the author of the work.

As it is noted in special literature, this "intuitive definition of a different stylistic color, is the first step towards the goal-directed formation of their intonationauditory experience" [4]. And this will bring children's fantasies and imagination to the level of high matter. According to V.V. Medushevsky, in any musical composition, "the very sequence of constructive units of music (if we ignore their semantics and communicative meanings) is able to reproduce the most general laws of development of the phenomena of the objective world and rationally control the processes of perception" [5]. Whatever individual associations each pers on has, they have a common bas is for all people - a concept about the logic of the passing of human emotions.

In their recognition by children, adaptation for the teaching and educational process developed by $\mathrm{V}$. V. Medushevsky's theory is very important [6]. The theory of "artistic modeling of emotions" in the music, which shows some "formulas" that fix the connections of the semantic (meaningful) meanings inside the musical emotion "Table I".

TABLE I. ARTISTIC MODELING OF EMOTIONS

\begin{tabular}{|l|l|l|}
\hline $\begin{array}{c}\text { Impulsive, excited, } \\
\text { fast movements }\end{array}$ & + joyful, light coloring & = gladness \\
\hline Sharp movements & + sad coloring & $=$ violent despair \\
\hline Wait ing & + stress & $=$ aspiration \\
\hline Intention & + misfit to goal & $=$ languor ... \\
\hline
\end{tabular}

While listening to and understanding of music through the inclusion of all sorts of associative connections, children's intuitive ideas about emotions, empathy4 for the inner world of music, are activated.

Further dialogue with students should be directed to the level of intonational analys is - to the way of understanding it by B.V. Asafiev: "I consider the intonational analys is as the perception of realized semantic music in its sounding process, in utterance, in comprehending what is heard, not just the statement of the ability to combine and correlate the ele ments and schemes of composition outside their audibility: such an analysis "outside intonation" is an anatomic incision: it can be realized by deaf even! It is necessary to aspire to narrate about music, so that its sound could be felt, and thereby to engage in the life of music" [7].

\footnotetext{
Empathy is a holistic perception of another inner world with preservation of emotional and semantic nuances, empathy for his psychic life.
} 
Consciousness of an unseeing child can perceive the music as a kind of "phenomenon in the world" (B. V. Asafiev), with it one can communicate in a dialogical way, experience life and live the life in it.

Auditory assimilation of intervals, chords, harmonic schemes requires a lot of effort. However, the emphasis on thorough memorization of the elements of the form can lead to a separation from the art of music as a phenomenon of intonation. While as singing, as speech become completely ine xpressive, meaningless, if there are no shades in it. "The musical pattern, devastated by amateur solfeging, ceases to be a phenomenon of art. The score reading should be viewed not as a goal itself, but as a means of conveying the artistic origin of a musical piece. Skills for musical text phrasing are developed consistently, as a result of a carefully thought-out system of educating musicality" [8]. There should be no joyless memorization of examples in the practice. So metimes a well-defined word that introduces a musical image helps a child simultaneously realize the significance of a particular means of musical and artistic expressiveness in the complex, and as a result - to learn feeling of the content of music deeper. This is how the development of skills of musicalauditory cognitive activity is developing and "intelligent ear" 5 is brought up.

The use of the method of verbal-figurative and semantic characteristics is fundamental in the formation of almost all compensatory factors (including interest, attention, musical memory, internal hearing, image-associative connections, speech designation, and auditory motor connections).

\section{THE METHOD OF RE-INTONING AND DEVELOPMENT OF CREATIVE IMAGINATION}

The essence of the method of re-intoning in solfeggio lessons is the systematic disclosure of the meaning of music to students through intonation in the process of its changes, development, rethinking. Through the comparative analysis of intonations within a single sound image (B. V. Asafiev), the recognition of a piece (of a known or composed melody) in a different style context - as a result of changes in the meter, tempo, dynamics, genre attributes, etc. The importance of this method is specially noted in the special literature. "This method, focusing on the most important sense-factor in music, forms the perception of music, adequate to its intonational nature. Since intonation is the most important regularity of musical art and is manifested in various ways in the activity of a composer, performer and listener, the method of "re-intoning" is used in all types of musical activity of students" [10].

\section{THE METHOD OF COLLABORATIVE CREATIVITY (ENSEMBLE SINGING)}

In the ensemble the singer feels himself a participant in a single creative process, adjusts his party to the general sound, trying to combine his singing with the singing of others organically. In ensemble singing, the acuity of hearing is

In this case solfeggio is considered by I.V. Voront sova - as a practical science of audit ory comprehension of music [9]. worked out, it is aimed at the fusion of voices; the inner ear, me mory, and sense of order are activated. Therefore, singing in the ensemble is an effective means of musical education at all stages of learning solfeggio. "Musical order appears as a whole system in a polyphony, as a result of which two-, three- and four-voice singing actively promotes the development of melodic and harmonious hearing, a modal and rhythmic feeling" [11].

Ensemble singing is useful to use at the initial stage of educating the sense of mode, when the teacher first of all pays attention to the development of the skill of intoning and the determination of the stable tones of the mode by ear. For example, alternate singing in a gamut in two groups or two students of stable and unstable steps of the mode.

Teachers on the instrument (specialty) working with blind children emphasize serious problems that impede studies and speeches. First of all, this is internal and muscular clamping. I.V. Syroezhkin, an experienced teacher, professor of the RSSAA, believes that "the feeling of muscular freedom is the first task and with its solution the musician's training should be started" [12]. As a way to acquire the feeling of muscle freedom, collaborative instrumental music playing is used. This practice should be actively used in solfeggio lessons. In collaborative creativity the unseeing child realizes also the possibility of communication, in which he is limited because of disease. In the ensemble of classmates they feel supported by each other.

\section{THE METHOD OF TACTILE-MOTOR PERFORMANCE}

In the process of cognitive activity the blind child most of all uses tactile sensitivity, which creates the effect of sensitization 6. Of course, this increase in sensitivity is associated with those areas of skin that are more actively involved in activities. The greatest increase in sensitivity was found on the fingers, which determined the importance of learning to read relief-dotted font by Braille.

With tactile-motor contact, the teacher himself helps the student to learn the techniques of conducting, timing. In the study of music, teachers often explain how to write a note, showing five lines on the fingers.

The method of tactile-motor performance is convenient for development at the initial classes of the mode hearing. Manual signs indicating the number of fingers corresponding to the number of the step will help mastering the ladder scale (behind the first stage one is fixed - the index finger, the second - two (index and middle), etc.). In order to understand the principle a child needs only one performance. Gradually, in his memory not only the name of the stage is fixed, but also the connection of its sound with the hand-sign performance [13].

6 Tiflopsychological research of touch by M.I. Zemt sova, Yu.A. Kulagina, L.I. Solntseva, V.M. Voronina, R.B. Kaffemanas showed that touch is a powerful means of compensating not only blindness, but also low vision. 


\section{CONCLUSION}

In conclusion, we note that the effectiveness of teaching depends on the creative approach of the teacher, his ability to organically combine the proposed methods with the individual capabilities of blind students.

\section{REFERENCES}

[1] O. I. Plaksina, Modern problems of psychological and pedagogical rehabilitation of students with visual impairment in the process of creat ive activity // Problems of professional and pedagogical training of musicians with visual impairment. Materials of the All-Russian Scientific and Practical Conference/ ed. A.V. Reprintseva. Kursk, 2001, p. 166.

[2] B. N. Kulakov, Formation of compensatory factors in blind musicians as a condition for optimizing the educational process (on the basis of work with blind bayanists, accordionists). Abstract. dis. kand. ped. Sciences. - M., 2000 .

[3] Creative education for gifted people with physical limitations. M., 2015, p. 26.

[4] Theory and methodology of music education of children. Scientificmethodological manual / L. V. Shkolyar, M.S. Krasilnikova, E. D. Kritskaya and oth. M., 1998, p. 120.

[5] Ibid. p. 172.

[6] V. V. Medushevsky, Intonation form of music. M., 1993.

[7] B. V. Asafiev, Selected works, vol. II, M., 1954, p. 142.

[8] S. E. Maksimov, Solfeggio for the vocalists, M., 1984, p. 5-6.

[9] I. V. Vorontsova, Musical hearing as an instrument of cognitive activity // Music of a changing Russia: Materials of the All-Russian Scientific and Practical Conference / Chief editor M. L. Kosmovskaya. Executive editor V.A. Lapteva i L.A.Khodyrevskaya. Kursk: Kursk University Press, 2007, pp. 61-66, 64.

[10] Theory and methodology of music education of children, p. 155.

[11] B. Nezvanov, Intonation in the course of solfeggio. L.: 1985, p. 139.

[12] I. V. Syroezhkin, Formation and development of performing skills for bayanists with limited vision. Art, design and modern education. Materials of the international interuniversity scientific-practical conference. April 22-24, 2015 / Moscow, RSSAA, 2015, pp. 551-563, 552.

[13] G. U. Lukina, V. I. Lisovoi, Methodology of teaching solfeggio for visually impaired and blind children in children's music school: Scientific and methodical manual, M., 2017. 